\title{
Coronary arteriovenous fistulas in the adults: natural history and
} management strategies

\author{
Yusuf Ata*1, Tamer Turk' ${ }^{1}$, Murat Bicer2 ${ }^{2}$, Mihriban Yalcin ${ }^{1}$, Filiz Ata ${ }^{3}$ and \\ Senol Yavuz ${ }^{1}$
}

Address: ${ }^{1}$ Bursa Yuksek Ihtisas Education and Research Hospital, Department of Cardiovascular Surgery, Bursa, Turkey, ${ }^{2}$ Uludag University Medical Faculty, Department of Cardiovascular Surgery, Bursa, Turkey and ${ }^{3}$ Bursa Yuksek Ihtisas Education and Research Hospital, Department of Anesthesiology, Bursa, Turkey

Email: Yusuf Ata* - yasefata@yahoo.com; Tamer Turk - tturkon@yahoo.com; Murat Bicer - mbicer23@yahoo.com;

Mihriban Yalcin - mihribandemir33@hotmail.com; Filiz Ata - filizatafiliz@hotmail.com; Senol Yavuz - syavuz@ttmail.com

* Corresponding author

Published: 6 November 2009

Journal of Cardiothoracic Surgery 2009, 4:62 doi:10.1186/1749-8090-4-62
Received: 9 September 2009

Accepted: 6 November 2009

This article is available from: http://www.cardiothoracicsurgery.org/content/4/I/62

(c) 2009 Ata et al; licensee BioMed Central Ltd.

This is an Open Access article distributed under the terms of the Creative Commons Attribution License (http://creativecommons.org/licenses/by/2.0), which permits unrestricted use, distribution, and reproduction in any medium, provided the original work is properly cited.

\begin{abstract}
Objective: To describe aspects of the natural history and pathophysiology of coronary arteriovenous fistula and to propose potential treatment strategies.
\end{abstract}

Methods: Eleven adult patients were treated surgically for coronary arteriovenous fistulas ( 8 male, 3 female) during the last three years. Mean age was 48,7 \pm 9,5 years (range 32-65 years). Diagnosis was made by coronary angiography and transesophageal echocardiography

Results: All patients were symptomatic due to the associating cardiac disorder or fistula. Presenting symptoms were chest pain, exertional dyspnea and palpitation. All patients were diagnosed by selective angiography. Transthoracic and transoesophageal echocardiography was performed to identify the $\mathrm{Qp} / \mathrm{Q}$ s ratio in one patient. One patient who had an LAD to pulmonary artery coronary arteriovenous fistula with a vascular malformation needed early reoperation due to recurrence of the fistula. Echocardiographic evaluation at the postoperative third month revealed no residual shunts in all patients.

Conclusion: Because of the severe complications that may develop due to coronary arteriovenous fistula, we believe that every coronary artery fistula should be treated invasively by surgery or transcatheter closure. But both treatment modalities still need to be evaluated with randomized multicenter studies for long term survival and effectiveness.

\section{Introduction}

Coronary arteriovenous fistula (CAVF) is rare anomaly which consists of abnormal communication between coronary artery and one of the cardiac chambers or vessels adjacent to the heart. Coronary arteriovenous fistulas (CAVFs) are present in $0.002 \%$ of the general population and are visualized in nearly $0.25 \%$ of patients undergoing catheterization [1-5].

Most of the patients with CAVFs are older than 20 years. Although they remain asymptomatic, symptoms and complications may develop with increasing age, and 
when surgery is performed in later life mortality and morbidity is increased $[6,7]$. We present our experience in eleven adult patients with CAVFs, document diagnostic evaluation and management strategies. The objective of this study was to describe aspects of the natural history and pathophysiology of CAVF and to propose potential treatment strategies.

\section{Methods \\ Patients}

In the last three years 11 adult patients with CAVFs were treated surgically in two hospitals. The mean age was 48,7 \pm 9,5 years (range 32-65 years). Coronary angiography was performed in all patients due to presenting symptoms and associated cardiac disorder. Transthoracic and transoesophageal echocardiography was performed to identify the Qp/Qs ratio in one patient.

All patients were symptomatic, presenting symptoms were angina, exertional dyspnea and palpitation. Clinical symptoms mostly depended on the associated cardiac disorder.

\section{Results}

Coronary angiography revealed 12 CAVFs originating from the proximal left descending artery $(\mathrm{n}=8)$ (Fig 1), the left main coronary $(\mathrm{n}=1)$, and the right coronary artery $(n=3)$. One patient $(9,1 \%)$ had bilateral fistulas with origin from the right coronary artery and the left descending artery. The majority of the CAVFs $(n=11)$ drained into the main pulmonary artery. Only in one case $(6.6 \%)$ fistula drained from right coronary artery into coronary sinus with an aneurysm of the right coronary artery (Fig 2). RCA to Coronary Sinus fistula patient was evaluated with transthoracic and transosephageal echocardiog-

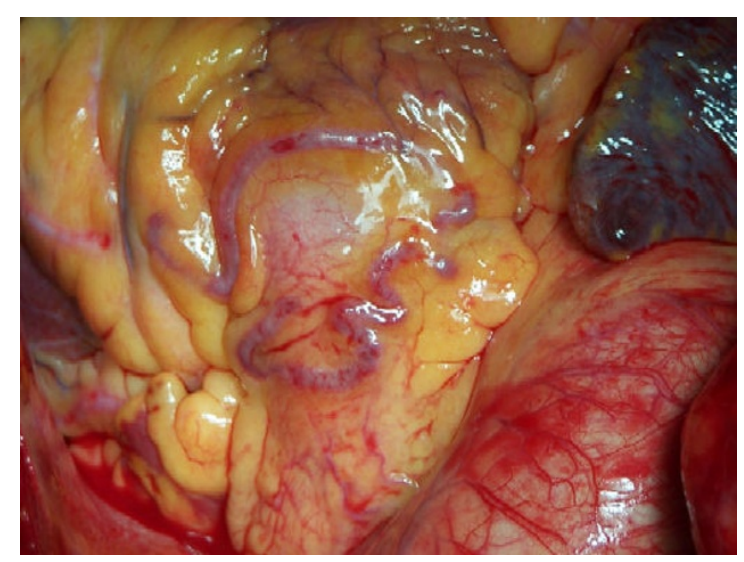

Figure I

Coronary arteriovenous fistula between LAD and pulmonary artery.

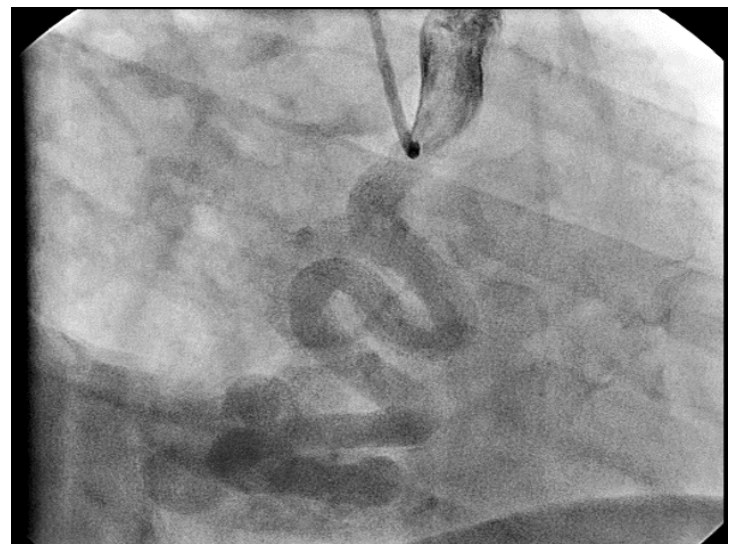

Figure 2

Dilated right coronary artery and coronary arteriovenous fistula draining into the coronary sinus.

raphy which showed normal contractile function with a Qp/Qs ratio 2.4/1.

Surgical correction was performed in all patients via median sternotomy. Seven patients were operated with the use of the cardiopulmonary bypass (CPB). Heparin was administrated $(300 \mathrm{U} / \mathrm{kg}$ ) before aortic cannulation. Anticoagulation was maintained during $\mathrm{CPB}$ and monitored with activated clotting time measurements (Hemochron 801, International Technique Corp, Edison, NJ, USA). We performed moderate systemic hypothermia $\left(30^{\circ} \mathrm{C}-32^{\circ} \mathrm{C}\right)$ in all the patients. A roller pump, a nonheparinized circuit and a hollow-fiber oxygenator were used. The pump flow was kept between 2.0-2.5 L/min/m2 body surface area to maintain a mean arterial pressure of 50 to $70 \mathrm{mmHg}$. Ascending aorta was clamped after the clamping of the CAVF near to the drainage area. Myocardial protection was achieved by an initial antegrade infusion of the St. Thomas' crystalloid cardioplegia and then continued with intermittent antegrade cold blood cardioplegia.

Other four patients were operated on beating heart without the use of CPB. After a median sternotomy heparin $(150 \mathrm{U} / \mathrm{kg})$ was administered. The Octopus Tissue Stabilizer (Octopus-4, Medtronic, Cardiac Surgical Products, MI, USA) was used for the stabilization of the target coronary artery. Heparin was antagonized with protamin sulphate until the activated clotting time decreased below 200 seconds.

All CAVFs are visible at the surface of the heart and a continuous thrill was palpable over all of the CAVFs. All CAVFs were dissected near their origins and were temporarily occluded with bulldog clamps until the thrill disap- 
peared for 20 minutes. After this period CAVFs were ligated both proximally and distally at the origin and the drainage site. The operations performed in association with closure of the CAVFs are listed in Table 1.

There was no surgical death; only one patient with recurrence of the fistula that was operated on beating heart needed early reoperation. This patient had a vascular malformation located on the main pulmonary trunk, after clamping and surgical ligation of the fistula the thrill disappeared but in the ICU the thrill appeared again. Coronary angiography revealed a fistula between LAD and the pulmonary artery. The patient was reoperated with CPB and the pulmonary connection of the fistula was ligated after opening the pulmonary trunk. All patients underwent echocardiography at the postoperative third month which revealed no residual shunts in all patients.

\section{Discussion}

CAVF is a very rare anomaly. It was firstly described by Krause in 1865 and the first surgical treatment was also done by Bjork and Crafoord in 1947 [8,9]. CAVFs constitute nearly half of all coronary artery anomalies and are the most common of hemodynamically significant coronary lesions [1-7]. Approximately half of all patients with CAVF remain asymptomatic and some CAVF might disappear spontaneously during childhood $[4,5,7,10,11]$.

CAVF may be congenital or acquired. CAVFs are associated with an other congenital heart disease in 20\% to $45 \%$ and isolated in $55 \%$ to $80 \%$ of the cases $[3,4,6,12]$. Associated anomalies include atrial septal defect, tetralogy of Fallot, patent ductus arteriosus, ventricular septal defect, and pulmonary atresia $[1,3,4,6]$.

Table I: Origin, drainage site of the CAVFs and the surgical treatment performed

\begin{tabular}{ccccc}
\hline Patient & Age & Origin & Drainage & Treatment \\
\hline 1 & 46 & LAD & PA & SC+OPCABG \\
2 & 50 & LAD & PA & SC+OPCABG \\
3 & 53 & LAD & PA & SC+OPCABG \\
4 & 51 & RCA & PA & SC+MVR+CABG \\
5 & 46 & LMCA & PA & SC+CABG \\
6 & 56 & LAD & PA & SC+CABG \\
7 & 58 & LAD & PA & SC+CABG \\
8 & 37 & LAD & PA & SC+OPCABG \\
9 & 42 & LAD and RCA & PA-PA & SC+CABG \\
10 & 32 & RCA & CS & SC \\
11 & 65 & LAD & PA & SC+CABG \\
\hline
\end{tabular}

$L A D$, left anterior descending coronary artery; PA, pulmonary artery; $S C$, surgical closure; OPCABG, off-pump coronary artery bypass grafting; RCA, right coronary artery; MVR, mitral valve replacement; LMCA, left main coronary artery; CABG, on-pump coronary artery bypass grafting
Origin of the CAVF can be any of the three major coronary arteries, including the left main trunk. The majority of these fistulas arise from the right coronary arteries or the left anterior descending; the circumflex coronary artery is rarely involved $[1,4-6]$. Single origin is the most common form of CAVF, ranging from $74 \%$ to $90 \%$ of the cases $[1,4,6,12]$. The right coronary artery or its branches is the most common site of the CAVFs with 55\% and the second common site is the left coronary artery in about 35\% of the cases [5]. In contrast with the majority of the literature but similar to the observations of Tirolimis et al. and Carrel et al. most of the CAVFs (75\%) in our study group were originating from the left coronary artery and only 3 (25\%) CAVFs were originating from the right coronary artery $[13,14]$. This might be because our small population study group is only consisted of adult patients. Multiple fistulas may be present in $10.7 \%$ to $16 \%$, and fistulas might originate from both coronaries in $4 \%$ to $18 \%$ of the cases [1-6]. One (9\%) of our cases also has double CAVFs originating both from right coronary artery and left coronary artery (Table 1$)$.

Over $90 \%$ of the fistulas drain into the venous structures of circulation. These include right-sided chambers, pulmonary artery, coronary sinus, and superior vena cava but drainage into the left-sided chambers is less frequent. Fistulous drainage occurs into the right ventricle in $40 \%$, right atrium in $26 \%$, pulmonary artery in $17 \%$, left ventricle in $3 \%$, coronary sinus in $7 \%$, and superior vena cava in $1 \%$ [4-6]. Drainage site was into the pulmonary artery in 10 patients and into the coronary sinus in one (Table 1). This difference should be due to our older aged study group which was shown by Urrutia et al. that drainage into the main pulmonary artery are a relatively common occurrence, especially in patients with increasing age [3].

Coronary artery dilatation is common but degree of dilatation does not always depend on the shunt size. In one of our case that was draining into the coronary sinus there was a notable dilatation in the right coronary artery (Fig 2).

The majority of the adult patients remain asymptomatic according to size and localization of the CAVF. Symptomatic adult patients may have symptoms of dyspnea, fatigue, and angina these symptoms might be due to concomitant presence of underlying cardiac disease $[3,7,13]$.

CAVF may result in severe complications; such as pulmonary hypertension because of an existing large left to right shunt, congestive heart failure, subacute bacterial endocarditis, myocardial ischemia resulting from steal phenomena, rupture or thrombosis of the CAVF or associating arterial aneurysm [5,6]. Symptoms and risk of these lethal complications increase with age $[6,7,13]$. 
The diagnosis of CAVF challenging as its prevalence is low, yet it should be considered in many symptomatic or asymptomatic patients presenting with cardiac murmurs. Differential diagnosis includes patent ductus arteriosus, pulmonary arteriovenous fistula, ruptured sinus of Valsalva aneurysm, aortopulmonary window, prolapse of the right aortic cusp with a supracristal ventricular septal defect, internal mammary artery to pulmonary artery fistula, and systemic arteriovenous fistula $[5,6,15]$.

Traditional way of diagnosis of CAVF is invasive investigations such as cardiac catheterization and coronary angiography. Most of the fistulas are small and found incidentally during coronary angiography. Coronary angiography still remains the gold standard for imaging the coronary arteries, but sometimes origin and relation of CAVF to adjacent cardiac structures may be ambiguous. It is difficult to measure and observe abnormal tortuous blood vessels with coronary angiography in one section, under such conditions non-invasive methods such as transthoracic echocardiography combined with Doppler and color flow imaging, transoesophageal echocardiography, magnetic resonance imaging and contrast enhanced multislice tomography can be used as adjunct to coronary angiography $[5,6,16-18]$.

Although the natural history of the CAVF is variable and some spontaneous closure is reported it is widely recommended by most of the authors that symptomatic CAVF should be treated, but is still controversial in patients without symptoms $[3,7,10,11,19-21]$. Some authors recommend closure of CAVF even in asymptomatic patients to prevent fistula related complications those will increase with age, especially because of the risk of heart failure, endocarditis and myocardial ischemia $[3,6,13,22]$. The authors of the present study accepted this recommendation and proposed closure of the diagnosed CAVFs. Most of the patients presented in our study had concomitant cardiac diseases therefore these diagnosed CAVFs were important in the planning and the performance of the surgical treatment of the coexisting cardiac disease. On the other hand in these cases the closure of the CAVFs should be performed to reduce postoperative early and late complications.

Surgical closure of CAVF by epicardial and endocardial ligations are gold standard for the treatment of CAVF and remains safe and effective with good reported success $[13,22-24]$. Some authors have reported successful surgical occlusion of CAVF on beating heart without cardiopulmonary bypass $[2,25]$. Ligation of the CAVF may be performed on the outside of the heart without CPB bypass when there is a simple and easily accessible CAVF. But we recommend exploration of the pulmonary artery with the use of cardiopulmonary bypass especially in patients hav- ing a CAVF in combination with a vascular malformation as in our patient that needed reoperation because after the surgical occlusion of the dominant left to right shunt in the CAVF omitted communication in the vascular malformation can cause late recurrence.

There is an increase in TCC treatment of CAVF in recent years with the use of advanced interventional devices $[21,26]$. TCC closure technique needs several conditions: anatomy of the fistula should be favorable for this treatment (eg. nontortuose vessel, the fistula should be unique with distal narrowing to avoid embolism to the drainage site, and distal portion of the fýstula should be accessible with the closure device $[20,21,26]$.

\section{Conclusion}

In the light of the literature we recommend the following as a treatment strategy: (1) patient with a symptomatic or an asymptomatic CAVF and an additional cardiac pathology that needs surgical intervention should refer to surgical closure; (2) patient with a symptomatic or asymptomatic CAVF and unsuitable anatomy for TCC closure should refer to surgical closure; (3) patient with a symptomatic or an asymptomatic CAVF and a suitable anatomy TCC should refer to TCC; (4) patient with a symptomatic or an asymptomatic CAVF with a coexisting cardiac pathology that needs percutaneous coronary intervention should refer to TCC; and (5) patient with a failed TCC should refer to surgical closure.

In conclusion, surgical closure of the CAVF can be performed with very low risk especially on the beating heart and in cases of isolated CAVF with suitable anatomy TCC is the alternative treatment selection. But yet surgery and especially TCC closure needs to be evaluated with randomized multicenter studies for long-term survival and effectiveness of the both therapeutic modalities.

\section{Competing interests}

Next Pharma financed the article processing charge of this article.

\section{Authors' contributions}

YA participated in collecting the data, writing, reviewing and submitting the manuscript. TT conceived of the study, participated in writing and submitting the manuscript. $\mathrm{MB}$ participated in collecting the data and reviewing the manuscript. MY participated in collecting the data and reviewing the manuscript. FA participated in reviewing and in writing of the manuscript. SY participated in reviewing of the manuscript. All authors read and approved the final manuscript.

\section{References}

I. Fernandes ED, Kadivar H, Hallman GL, Reul GJ, Ott DA, Cooley DA: Congenital malformations of the coronary arteries: the 
Texas Heart Institute experience. Ann Thorac Surg 1992, 54:732-740.

2. Olearchyk AS, Runk DM, Alavi M, Grosso MA: Congenital bilateral coronary-to-pulmonary artery fistulas. Ann Thorac Surg 1997, 64:233-235.

3. Urrutia-S CO, Falaschi G, Ott DA, Cooley DA: Surgical management of 56 patients with congenital coronary artery fistulas. Ann Thorac Surg 1983, 35:300-307.

4. Dodge-Khatami A, Mavroudis C, Backer CL: Congenital Heart Surgery Nomenclature and Database Project: anomalies of the coronary arteries. Ann Thorac Surg 2000, 69:270-297.

5. Gowda RM, Vasavada BC, Khan IA: Coronary artery fistulas: clinical and therapeutic considerations. Int J Cardiol 2006, 107:7-I0.

6. Levin DC, Fellows KE, Abrams HL: Hemodynamically significant primary anomalies of the coronary arteries. Angiographic aspects. Circulation 1978, 58:25-34.

7. Liberthson RR, Sagar K, Berkoben JP, Weintraub RM, Levine FH: Congenital coronary arteriovenous fistula: report of 13 patients, review of the literature and delineation of management. Circulation 1979, 59:849-853.

8. Krause W: Ueber den Ursprung einer akzessorischen A. coronaria aus der A. pulmonalis. Z Ratl Med I865, 24:225-9.

9. Bjork G, Crafoord C: Arteriovenous aneurysm on the pulmonary artery simulating patent ductus arteriosus botalli. Tho$\operatorname{rax}$ 1947, 2:65.

10. Farooki ZQ, Nowlen T, Hakimi M, Pinsky WW: Congenital coronary artery fistulae: a review of 18 cases with special emphasis on spontaneous closure. Pediatr Cardiol 1993, 14:208-2I3.

II. Griffiths SP, Ellis K, Hordof AJ, Martin E, Levine OR, Gersony WM: Spontaneous complete closure of a congenital coronary artery fistula. I Am Coll Cardiol 1983, 2: | 169- I I73.

12. Vitarelli A, De Curtis G, Conde Y, Colantonio M, Di Benedetto G, Pecce P, De Nardo L, Squillaci E: Assessment of congenital coronary artery fistulas by transesophageal color Doppler echocardiography. Am J Med 2002, I I 3: I 27-33.

13. Tirilomis T, Aleksic I, Busch T, Zenker D, Ruschewski W, Dalichau H: Congenital coronary artery fistulas in adults: surgical treatment and outcome. Int J Cardiol 2005, 98:57-9.

14. Carrel T, Tkebuchava T, Jenni R, Arbenz U, Turina M: Congenital coronary fistulas in children and adults: diagnosis, surgical technique and results. Cardiology 1996, 87:325-30.

15. Guray U, Guray Y, Ozbakir C, Yilmaz MB, Sasmaz H, Korkmaz S: Fistulous connection between internal mammary graft and pulmonary vasculature after coronary artery bypass grafting: a rare cause of continuous murmur. Int J Cardiol 2004, 96:489-92.

16. Aydogan U, Onursal E, Cantez T, Barlas C, Tanman B, Gurgan L: Giant congenital coronary artery fistula to left superior venacava and right atrium with compression of left pulmonary vein simulating cor triatratum: diagnostic value of magnetic resonance imaging. Eur J Cardiovasc Surg 1994, 8:97-9.

17. Ropers D, Moshage W, Daniel WG, JessI J, Gottwik M, Achenbach S: Visualization of coronary artery anomalies and their anatomic course by contrast-enhanced electron beam tomography and three-dimensional reconstruction. Am J Cardiol 200I, 15:193-197.

18. Chee TS, Tan PJ, Koh SK, Jayaram L: Coronary artery fistula diagnosed by transthoracic Doppler echocardiography. Singapore Med J 2007, 48:262-264.

19. Bogers AJJC, Quaegebeur JM, Huysans HA: Early and late results of surgical congenital coronary artery fistula. Thorax 1987, 42:369-373.

20. Mavroudis C, Backer CL, Rocchini AP, Muster AJ, Gevitz M: Coronary artery fistulas in infants and children: a surgical review and discussion of coil embolization. Ann Thorac Surg 1997, 63: $1235-1242$

21. Armsby LR, Keane JF, Sherwood MC, Forbess JM, Perry SB, Lock JE: Management of coronary artery fistulae. Patient selection and results of transcatheter closure. J Am Coll Cardiol 2002, 39:1026-1032

22. Balanescu S, Sangiorgi G, Castelvecchio S, Medda M, Inglese L: Coronary artery fistulas: clinical consequences and methods of closure: a literature review. Ital Heart J 200I, 2:669-76.

23. Kamiya $H$, Yasuda $T$, Nagamine $H$, Sakakibara N, Nishida S, Kawasuji $M$, Watanabe G: Surgical treatment of congenital coronary artery fistulas: 27 years' experience and a review of the literature. J Card Surg 2002, 17:173-177.
24. Benlafqih C, Leobon B, Chabbert V, Glock Y: Surgical exclusion of a symptomatic circumflex coronary to right atrium fistula. Interact CardioVasc Thorac Surg 2007, 6:413-4I5.

25. Hoendermis ES, Waterbolk TW, Willems TP, Zijlstra F: Large common left and right coronary artery to coronary sinus fistula. Interact Cardiovasc Thorac Surg 2006, 6:788-9.

26. Perry SB, Rome J, Keane JF, Baim DS, Lock IE: Transcatheter closure of coronary artery fistulas. J Am Coll Cardiol 1992, 20:20I-209.

Publish with Bio Med Central and every scientist can read your work free of charge

"BioMed Central will be the most significant development for disseminating the results of biomedical research in our lifetime. "

Sir Paul Nurse, Cancer Research UK

Your research papers will be:

- available free of charge to the entire biomedical community

- peer reviewed and published immediately upon acceptance

- cited in PubMed and archived on PubMed Central

- yours - you keep the copyright 